\title{
TINJAUAN PELAKSANAAN PEMISAHAN DAN PEMUSNAHAN BERKAS REKAM MEDIS AKTIF DAN INAKTIF DI RUMAH SAKIT RAFFLESIA BENGKULU
}

\author{
Nofri Heltiani, Cindy Dellany Oktavia \\ Akademi Kesehatan Sapta Bakti Bengkulu
}

\begin{abstract}
ABSTRAK
Berkas rekam medis inaktif pada rak penyimpanan tidak selamanya akan disimpan, karena jumlah rekam medis di rumah sakit terus bertambah. Pemisahan dan pemusnahan rekam medis merupakan salah satu upaya yang dilakukan oleh pihak rumah sakit dengan tujuan mengurangi penumpukan berkas rekam medis di ruang penyimpanan.Rumah Sakit Rafflesia Bengkulu hanya mempunyai satu ruang penyimpanan rekam medis aktif dan tidak mempunyai ruang penyimpanan rekam medis inaktif secara khusus.Rekam medis inaktif disimpan di ruang penyimpanan rekam medis aktif dikarenakan ruang tersebut sudah penuh, dan ada sebagian rekam medis inaktif yang disimpan di dalam kardus serta hanya diletakkan di lantai dekat rak penyimpanan.Untuk mengurangi berkas rekam medis inaktif tersebut rumah sakit melakukan pemusnahan. Tujuan penelitian ini adalah untuk mengetahui tinjauan pelaksanaan pemisahan dan pemusnahan berkas rekam medis aktif dan inaktif di Rumah Sakit Rafflesia Bengkulu. Jenis penelitian yang digunakan pada penelitian ini adalah deskriptif kualitatif dengan rancangan cross sectional, populasi dalam penelitian ini adalah berkas rekam medis periode tahun 2012-2016 sebanyak 78.408, dengan sampel sebanyak 78.408 berkas rekam medis dengan teknik pengambilan sampel total populasi. Menggunakan data primer dan sekunder, diolah secara reduksi data, penyajian data dan penarikan kesimpulan atau verifikasi.Hasil penelitian ini adalah pemisahan dan pemusnahan berkas rekam medisaktif-inaktif belum sesuai dengan SOP karena banyak tahapan yang tidak laksanakan.Fasilitas yang digunakan untuk melakukan pemusnahan meliputi tempat, alat pencacah dan komputer. Pelaksanaan penilaian berkas rekam medis yang akan dimusnahkan berdasarkan tata cara penilaian yang terdapat pada prosedur pemusnahan berkas rekam medis.Diharapkan Rumah Sakit Rafflesia Bengkulumemiliki SOP tentang pemisahan dan pemusnahan berkas rekam medis.
\end{abstract}

\section{PENDAHULUAN}

Menurut Peraturan Menteri Kesehatan Republik Indonesia Nomor. 269/Menkes/Per/III/2008 Tentang Rekam Medis pada Pasal 1, dimana rekam medis adalah berkas yang berisikan catatan dan dokumen tentang identitas pasien, pemeriksaan, pengobatan, tindakan dan pelayanan lain yang telah diberikan kepada pasien. Setiap rumah sakit harus membuat rekam medis,baik rekam medis rawat jalan maupun rekam medis rawat inap.Rekam medis juga berguna sebagai bukti tertulis atas tindakan-tindakan pelayanan terhadap pasien, juga mampu melindungi kepentingan hukum bagi pasien yang bersangkutan, rumah sakit maupun dokter dan tenaga kesehatan lainnya, apabila dikemudian hari terjadi suatu hal yang tidak diinginkan menyangkut rekam medis itu sendiri.

Rekam medis ada dua jenis yaitu rekam medis aktif dan inaktif.Rekam medis aktif adalah rekam medis yang masih 
dipergunakan karena frekuensi kunjungannya masih memungkinkan dipertahankannya rekam medis tersebut, sedangkan rekam medis inaktif adalah rekam medis yang telah mencapai waktu tertentu tidak pernah digunakan lagi karena pasiennya tidak pernah berkunjung ke rumah sakit tersebut (Skurka, 2003).

Rekam medis harus disimpan sesuai dengan peraturan yang ada. Untuk sarana pelayanan kesehatan dirumah sakit, rekam medis pasien rawat inap harus disimpan sekurang-kurangnya lima tahun sejak pasien berobat terakhir atau pulang dari berobat di rumah sakit. Setelah lima tahun, rekam medis dapat dimusnahkan kecuali ringkasan pulang dan persetujuan tindakan medis (Barthos, 2007).

Pemisahan adalah suatu kegiatan memilah dan memilih kemudian memisahkan antar berkas rekam medis yang tidak bernilai guna dengan berkas bernilai guna (Barthos, 2007).

Seiring dengan pernyataan Sulistyo \&Basuki (2003), penyusutan arsip dinamis merupakan kegiatan pengurangan arsip dinamis dengan cara memindahkan arsip dinamis aktif yang memiliki frekuensi penggunaan rendah ke penyimpanan arsip dinamis inaktif, memindahkan arsip dinamis inaktifdari unit pengolah atau penerima ke pusat arsip dinamis inaktif,memusnahkan arsip dinamis bila sudah jatuh waktu, menyerahkan arsip dinamis inaktif dari unit arsip dinamis inaktifke depo arsip statis.

Menurut Kartono (2010),pemusnahan berkas rekam medis inaktifdipengaruhi oleh Sumber Daya Manusia (SDM), fasilitas dan penilaian berkas rekam medis sesuai dengan Standar Oprasional Prosedur (SOP).Hal ini sesuai dengan pendapat Rahayu (2012), yang menyatakan bahwa dalam pelaksaan penyusutan berkas rekam medis inaktifharus mempunyai kebijakan, SOP, fasilitas dan penilaian berkas rekam medis inaktif.

Rumah Sakit Rafflesia Bengkulu penyimpanan berkas rekam medis rawat jalan rawat inap dan Instansi Gawat Darurat(IGD) menggunakan sistem sentralisasi, namun apabila ruang penyimpanan tersebut sudah penuh maka sebagian rekam medis disimpan di dalam kardus dan/atau diletakkan di lantai dekat rak penyimpanan.

. Dari awal berdirinya sampai dengan saat ini Rumah Sakit Rafflesia Bengkulutelah melakukan pemusnahan sebanyak tiga sampai dengan empat kali, akan tetapi pemusnahan berkas rekam medis yang dilakukan Rumah Sakit Rafflesia Bengkulu tidak sesuai dengan Peraturan Menteri Kesehatan Republik Indonesia Nomor 269/Menkes/Per/III/2008 Tentang Rekam Medis. Maka dari itu penulis tertarik untuk menelti tentang "Tinjauan Pelaksanaan Pemisahan dan Pemusnahaan Berkas Rekam Medis Aktif dan Inaktif di Rumah Sakit Rafflesia Bengkulu”. 
Peneliti ini bertujuan untuk mengetahui tinjauan pelaksanaan pemisahaan dan pemusnahan berkas rekam medis aktif dan inaktifdi Rumah Sakit Rafflesia Bengkulu.

\section{METODE PENELITIAN}

Penelitian ini menggunakan jenis penelitian deskriptif kualitatif yaitu menggambarkan objek yang diteliti secara langsung dengan mengguanakan observasional dengan rancangan cross sectional. Dimana pendekatan ini dilakukan dengan melihat kondisi pada saat dilaksanakan penelitian yang dapat dilakukan sewaktu-waktu. Populasi penelitian ini yaitu berkas rekam medis periode tahun 2012 s.d
2016 sebanyak 78.408. Teknik pengambilan sampel dalam penelitian ini adalah total populasi. Total populasi adalah teknik pengambilan sampel dimana jumlah sampel sama dengan populasi (Sugiyono, 2007). Jenis data penelitian ini yaitu teknik pengumpulan data yang digunakan adalah data primer dan data sekunder. Data primer dilakukan dengan cara wawancara kepada petugas Rekam Medis Rumah Sakit Rafflesia Bengkulu. Data sekunder dilakukan dengan cara melihat pada berita acara pemusnahan berkas rekam medis. Penelitian ini dilakukan di Rumah Sakit Raffesia Kota Bengkulu. Setelah data terkumpul data disajikan dalam bentuk table dan narasi.

\section{HASIL PENELITIAN}

a. Gambaran Pelaksanaan Pemisahan Berkas Rekam Medis Aktif-Inaktif di Rumah Sakit Rafflesia Bengkulu

Tabel 1 Hasil Observasi Pelaksanaan Pemisahan Berkas Rekam Medis Aktif-Inaktif di Rumah Sakit Bengkulu

\begin{tabular}{|c|l|c|c|}
\hline No & \multicolumn{1}{|c|}{ Prosedur Pemisahan } & Ya & Tidak \\
\hline \hline A. & SDM & \multicolumn{1}{|c|}{} \\
\hline 1. & $\begin{array}{l}\text { Petugas rekam medis mengetahui tata cara pemisahan } \\
\text { berkas rekam aktif-inaktif }\end{array}$ & $\sqrt{ }$ & \\
\hline 2. & $\begin{array}{l}\text { Petugas rekam medis mengetahui berkas yang } \\
\text { dipisahkan sesuai dengan kriteria berkas inaktif }\end{array}$ & $\sqrt{ }$ \\
\hline B. & Fasilitas yang digunakan & $\sqrt{ }$ & $\sqrt{ }$ \\
\hline 1. & Ada tempat khusus untuk melakukan pemisahan berkas & $\sqrt{ }$ & \\
\hline 2. & Ada alat-alat untuk melakukan pemisahan & $\sqrt{ }$ & $\sqrt{ }$ \\
\hline 3. & Ada daftar pertelaan & $\sqrt{ }$ & \\
\hline C. & Penilaian & \multicolumn{2}{|l|}{} \\
\hline 1. & Ada SOP pemisahan berkas aktif-inaktif & $\begin{array}{l}\text { Menyisihkan atau memisahkan } \\
\text { L Lembar RMK } \\
\text { - Lembar Operasi }\end{array}$ & \multicolumn{2}{|l}{} \\
\hline
\end{tabular}




\begin{tabular}{|c|l|c|c|}
\hline & $\begin{array}{l}\bullet \text { Lembar Resume } \\
\text { - Lembar Persetujuan } \\
\text { - Lembar Identifikasi Bayi } \\
\text { - Lembar Kematian }\end{array}$ & & \\
\hline 3. & $\begin{array}{l}\text { Berkas/lembar rekam medis pasien yang telah dipisahkan } \\
\text { dan masih bernilai guna disimpan dalam satu map }\end{array}$ & $\sqrt{ }$ \\
\hline 4. & $\begin{array}{l}\text { Berkas inaktif yang telah dipisahkan diletakan pada boks } \\
\text { dan diberi label }\end{array}$ & $\sqrt{ }$ \\
\hline 5. & $\begin{array}{l}\text { Berkas yang telah diletakan dalam boks diletakkan } \\
\text { diruang penyimpanan berkas inaktif }\end{array}$ & $\sqrt{ }$ \\
\hline
\end{tabular}

Berdasarkan table hasil observasi

inaktif, adanya alat-alat penunjang diatas dapat ditarik kesimpulan bahwa dari sepuluhprosedur observasi tentang cara pemisahan berkas, hanya ada empatyang pelaksanaanya sesuai dengan prosedur yaitu Petugas Rekam Medis mengetahui cara pemisahan berkas aktifpemisahan berkas, adanya berkas pertelaan dan menyisihkan atau memisahkan Lembar RMK, Lembar Operasi, Lembar Resume, Lembar Persetujuan, Lembar Identifikasi Bayi dan Lembar

Kematian.

\section{b. Gambaran Pelaksanaan Pemusnahan Berkas Rekam Medis Inaktif di Rumah Sakit Rafflesia} Bengkulu

Tabel 2 Hasil Observasi Pelaksanaan Pemusnahan Berkas Rekam Medis Inaktif di Rumah Sakit Bengkulu

\begin{tabular}{|c|l|c|c|}
\hline No & \multicolumn{1}{|c|}{ Prosedur Pemusnahan } & Ya & Tidak \\
\hline \hline A. & SDM & \multicolumn{3}{|c|}{} \\
\hline 1. & $\begin{array}{l}\text { Petugas rekam medis mengetahui tata cara pemusnahan } \\
\text { berkas rekam inaktif }\end{array}$ & $\sqrt{ }$ & \\
\hline 2. & Ada panitia khusus pemusnahan berkas & $\sqrt{ }$ & \\
\hline B. & Fasilitas yang digunakan & $\sqrt{ }$ & \\
\hline 1. & Ada tempat khusus untuk melakukan pemusnahan berkas & $\sqrt{ }$ & \\
\hline 2. & Ada alat-alat untuk melakukan pemusnahan & $\sqrt{ }$ & \\
\hline 3. & Ada daftar pertelaan & & $\sqrt{ }$ \\
\hline C. & Penilaian & $\sqrt{ }$ & \\
\hline 1. & Adanya pemusnahan berkas inaktif sesuai dengan standar & $\sqrt{ }$ & \\
\hline 2. & Ada SK pemusnahan berkas rekam medis inaktif & & \\
\hline 3. & $\begin{array}{l}\text { Berkas yang dimusnahkan sesuai dengan prosedur } \\
\text { dibakar/pencacahan/pembuburan }\end{array}$ & & $\sqrt{ }$ \\
\hline 4. & Adanya berita acara pemusnahan & & $\sqrt{ }$ \\
\hline 5. & Ada dokumentasi pemusnahan & & \\
\hline
\end{tabular}

Berdasarkan table hasil observasi

diatas dapat ditarik kesimpulan bahwa dari sepuluh prosedur observasi tentang cara pemusnahan berkas, hanya ada tiga (3) yang pelaksanaanyatidak sesuai dengan prosedur yaitu Tidak adanya SOP, 
Tidak adanya Berita Acara Pemusnahan, serta Tidak adanya Dokumentasi

\section{PEMBAHASAN}

1. Gambaran Pelaksanaan Pemisahan Berkas Rekam Medis Aktif-Inaktif di Rumah Sakit Rafflesia Bengkulu.

Dalam proses pemisahan berkas Rekam Medis yang Aktif-Inaktif terdapat beberapa prosedur. Namun pada saat dilakukannya penelitian di RS Rafflesia Bengkulu dari 10 Presedur Pemisahan hanya ada empat yang pelaksanaanya sesuai dengan prosedur yaitu Petugas Rekam Medis mengetahui cara pemisahan berkas aktif-inaktif, adanya alat-alat penunjang pemisahan berkas, adanya berkas pertelaan dan menyisihkan atau memisahkan Lembar RMK, Lembar Operasi, Lembar Resume, Lembar Persetujuan, Lembar Identifikasi Bayi dan Lembar Kematian.

Tidak sesuainya tindakan pemisahan demham prosedur dapat dipengaruhi oleh beberapa factor yaitu :

a. Berkas aktif-inaktif tidak dipilah sesuai dengan standar.

b. Berkas yang dipisahkan tidak sesuai dengan kriteria berkas inaktif, karena beberapa berkas yang seharusnya sudah dimusnahkan masih ditemukan di ruang penyimpanan berkas rekam medis.
Pemusnahan.

c. Tidak adanya tempat khusus untuk melakukan proses pemisahan berkas.

d. Tidak adanya map penyimpanan berkas yang telah dipilah.Berkas yang inaktif tidak disimpan di dalam boks khusus dan tidak ada pemberian label.

e. Tidak adanya ruang khusus penyimpanan berkas rekam medis inaktif.

Tidak adanya standar pelaksanaan pemisahan yang jelas sehingga menyebabkan berkas aktif-inaktif yang dipisahkan tidak sesuai dengan kriteria pemisahan berkas. Tidak adanya tempat khusus untuk melakukan pemisahan dan juga penyimpanan berkas aktif-inakif juga merupakan point penting pada proses pemisahan, agar berkas-berkas yang telah dipisahkan tidak bercampur antara berkas yang masih aktif dan berkas yang inaktif. Agar memudahkan pada saat proses pemusnahan, berkasberkas inkatif yang telah dipisahkan hendaknya diletakkan kedalam box dan diberi label lalu penyimpanan berkas inaktif tersebut diletakkan diruang khusus berkas-berkas inaktif. 


\section{Gambaran Pelaksanaan Pemusnahan} Berkas Rekam Medis Inaktif di Rumah Sakit Rafflesia Bengkulu.

Berdasarkan dari hasil penelitian yang telah peneliti lakukan di Rumah Sakit Rafflesia diperoleh hasil bahwa dari 10 prosedur pemusnahan hanya 3 prosedur yang tidak dilakukan oleh petugas Rekam Medis, yaitu Tidak adanya standar yang jelas pada proses pemusnahan, Tidak adanya Berita Acara Pemusnahan, serta Tidak adanya Dokumentasi Pemusnahan. Hal ini terjadi karena tidak adanya Standar yang jelas sehingga pemusnahan yang dilakukan tidak terorganisir dengan baik, selain itu juga dikarenakan penyimpanan berkas berita acara pemusnahan dan juga pendokumentasian yang tidak benar sehingga pada saat penelitian saya tidak bisa menemukan berita acara, standar proses pemusnahan pada Rumah Sakit dan juga pendokumentasian pada saat pemusnahan berkas berlangsung.

Persiapan pemusnahan berkas rekam medis yang dilakukan meliputi pemisahan berkas rekam medis aktifinaktif dari rak penyimpanan berkas rekam medis rawat inap inaktif yang ada di ruang penyimpanan berkas rekam medis aktif.Setelah berkas rekam medis dipisahkan kemudian dilakukan penilaian terhadap lembar rekam medis yang masih mempunyai nilai guna.

Setelah proses tersebut di atas bagian rekam medis juga membuat daftar pertelaan. Akan tetapi pembuatan daftar pertelaan tersebut belum sepenuhnya selesai.Dalam melakukan persiapan pemusnahan Rumah Sakit Rafflesia Bengkulu mempunyai prosedur tetap pemusnahan berkas rekam medis sebagai pedoman untuk melakukan pemusnahan.

Prosedur tetap pemusnahan berkas rekam medis Rumah Sakit Rafflesia Bengkulu sebagai berikut:

a.Dilihat dari tanggal kunjungan terakhir.

b. Berkas rekam medis yang tidak pernah berkunjung ke rumah sakit lebih dari lima tahun secara berturut-turut rekam medisnya dinyatakan inaktif.

c.Berkas rekam medis inaktif dikelompokkan sesuai dengan tahun terakhir kunjungan.

d. Lembar-lembar rekam medis yang dipilah:

1) Ringkasan masuk dan keluar RM01

2) Resume

3) Lembar laporan operasi

4) Lembar identifikasi bayi lahir hidup

5) Lembar persetujuan

6) Lembar sebab kematian

7) Hasil pemeriksaan yang penting (Lab, PA, RO) 
e.Berkas rekam medis tertentu disimpan di ruang berkas rekam medis inaktif.

f.Lembar rekam medis sisa dan dan berkas rekam medis rusak/tidak terbaca disiapkan untuk dimusnahkan. Berkas rekam medis rusak/tidak terbaca harus dibuat surat pernyataan oleh Direktur Rumah Sakit.

g. Tim pemusnah dibentuk dengan SK Direktur beranggotakan dari panitia rekam medis, perawat senior dan tenaga lain yang terkait.

h. Pelaksanaan pemusnahan berkam rekam medis dilakukan dengan caradibakar di halaman samping dekat Musholla Rumah Sakit Rafflesia sehingga menyebabkan polusi udara di lingkungan sekitar Rumah Sakit.

i. Tim pemusnah membuat berita acara pemusnahan.

j. Khusus untuk berkas rekam medis yang sudah rusak/tidak terbaca dapat langsung dimusnahkan dengan terlebih dahulu membuat pernyataan oleh Direktur Rumah Sakit. Persiapan pemusnahan berkas rekam medis yang dilakukan di Rumah Rafflesia Bengkulu belum sesuai dengan prosedur tetap pemusnahan yang ada di rumah sakit tersebut.

k. Berdasarkan prosedur tetap pemusnahan yang ada di rumah sakit, tim pemusnah dibentuk dengan SK Direktur yang beranggotakan dari panitia rekam medis, perawat senior dan tenaga lain yang terkait dan tim pemusnah membuat berita acara pemusnahan. Akan tetapi pada pelaksanaannya belum dibentuk tim pemusnah dan berita acara pemusnahan.

\section{SIMPULAN}

1. Petugas Rekam Medis Rumah Sakit Rafflesia Bengkulu terdiri dari pegawai honor dan juga pegawai tetap. Petugas Rekam Medis Rumah Sakit Rafflesia Bengkulu juga memiliki pemahaman dan pengetahuan yang baik mengenai proses pemisahan berkas aktif-inkatif dan pemusnahan berkas rekam medis inaktif.

2. Fasilitas pemilihan dan pemusnahan berkas rekam medis yang dimiliki Rumah Sakit Rafflesia Bengkulu juga sudah lengkap hanya saja belum adanya alat pencacah dan juga ruangan khusus untuk pemilahan dan juga penyimpanan berkas inaktif, sehingga beberapa berkas inaktif ada yang tercampur dengan berkas aktif.

3. Penilaian dan pelaksanaan pemilahan berkas rekam medis di Rumah Sakit Rafflesia Bengkulu belum dilakukan sesuai dengan SOP pemusnahan berkas.

4. Penilaian dan pelaksanaan pemusnahan berkas rekam medis Penilaian berkas rekam medis sudah sesuai dengan tata cara penilaian yang terdapat pada prosedur pemusnahan berkas rekam 
medis. Lembar yang mempunyai nilai guna meliputi lembar ringkasan masuk keluar, lembar laporan operasi, lembar resume, lembar persetujuan, lembar kematian, lembar identifikasi bayi.

\section{SARAN}

1. Sebaiknya dilakukan pengecekkan ulang oleh petugas rekam medis terhadap lembar-lembar rekam medis yang telah dinilai dan dilakukan oleh tenaga kontrak untuk menghindari terjadinya kesalahan dalam penilaian berkas rekam medis.

2. Menyediakan ruangan khusus untuk menyimpan berkas yang sudah inaktif dan menyediakan tempat khusus dilakukan pemusnahan berkas rekam medis.
3. Membuatkan SOP yang jelas tentang pemisahan dan pemusnahan berkas rekam medis.

\section{DAFTAR PUSTAKA}

Barthos, B. 2007. Manajemen Kearsipan Untuk Lembaga Negara, Swasta dan Perguruan Tinggi. Jakarta: Bumi Aksara.

Departemen Kesehatan Republik Indonesia. Permenkes RI, No. 269/MenKes/Per/III/2008, Tentang Rekam Medis. (Jakarta : Depkes RI. 2008).

Kartono. 2010. Pemusnahan Berkas Rekam Medis Inaktif di Rumah Sakit Panti Rini Kalasan. Karya Tulis Ilmiah (Tidak Dipublikasikan).

Rahayu. 2012. Tinjauan Pelaksana Penyusutan Berkas Rekam Medis di Siloam Hospital, Kebun Jeruk, Jakarta.

Skurka, M.A. 2003. Health Information Management. Sanfrancisco:

Sulistyo \& Basuki. 2003. Pengantar Kearsipan, Universitas Terbuka, Departemen Pendidikan dan Kebudayaan, Jakarta. 